\title{
APPLICATION OF DATA RECONCILIATION TO THE SIMULATION OF SYSTEM CLOSURE OPTIONS IN A PAPER DEINKING PROCESS
}

\author{
D.Brown ${ }^{1}$, F.Maréchal ${ }^{2}$, G.Heyen ${ }^{3}$, and J.Paris ${ }^{1}$ \\ 1. École Polytechnique, Montreal, Canada \\ 2. Swiss Federal Institute of Technology, Lausanne, Switzerland \\ 3. LASSC, Université de Liège, Belgium
}

\begin{abstract}
An equation solver data reconciliation software has been used to build a validated model of a waste paper deinking plant, by combining control room measurements and design specifications. An optimal sensor system configuration that allows validating key performance indicators by using only control room measurements has been determined by identifying, with genetic algorithm programming, the additional sampling points and corresponding sensors required for a minimum cost sensor system configuration.
\end{abstract}

\section{INTRODUCTION}

Computer aided process simulation is an efficient design tool, which can help pulp and paper industries, pressured by global competition, and urged to comply with environmental regulation, to upgrade their facilities rapidly, and at low engineering and operating cost (Jacob and Paris, in print). Namely, in the context of system water closure, accurate models are needed to predict the impacts of retrofit modifications on a given process. Data reconciliation is essential for process performance follow up and simulation model calibration. Based on measurement redundancy, it is recommended as a preliminary step to process simulation. The numerous benefits of real time plant data reconciliation have been discussed in detail by Heyen (2000). In the pulp and paper industry, it has been noted that there are few examples of large-scale simulations that are actually based on reconciled data collected from a process in operation (Jacob and Paris, in print). Due to the number of pieces of equipment and streams involved, and in spite of the abundance of information that can be acquired using process sensors, a considerable amount of additional measurements are often still required to reach satisfactory levels of redundancy. These levels can be achieved at an acceptable cost by combining data reconciliation with equipment design specifications and process diagrams. The problem with this approach is the validity of the assumptions and their impact on the measurement corrections and precision. To overcome this drawback, a method based on the sensitivity matrix analysis has been proposed by Heyen et al (2002) to identify the appropriate additional sampling points.

2. Address of correspondence: Dr. François Maréchal, Laboratory of Industrial Energy Systems, Institute of Energy Sciences, Swiss Federal Institute of Technology, CH-1015 Lausanne,

E-mail: francois.marechal@epfl.ch, Tel 412169335 16, Fax 41216933502 


\section{CASE STUDY}

The aim of this study was to calibrate a model of an old newspaper and magazine deinking plant by applying data reconciliation, and to design a sensor system capable of identifying key process performance indicators with satisfactory precision and at minimal cost.

The deinking plant is located in Quebec. It uses $80 \%$ old news paper and $20 \%$ old magazines furnish to produce deinked pulp. The plant is located next to a thermo mechanical pulp newsprint mill to which part of the deinked pulp is sent to produce 30 $\%$ recycled content paper. The recycling facility was built in the early nineties, and was subsequently modernized at the end of the decade in order to increase its production capacity. During the upgrade, several modifications were made to the pulp treatment sequences and the process water circulation layout. It is estimated that the fresh water intake has been reduced from approximately 21 to 15 tons per ton of oven dried pulp produced. Figure 1 shows a simplified layout of the present day plant.
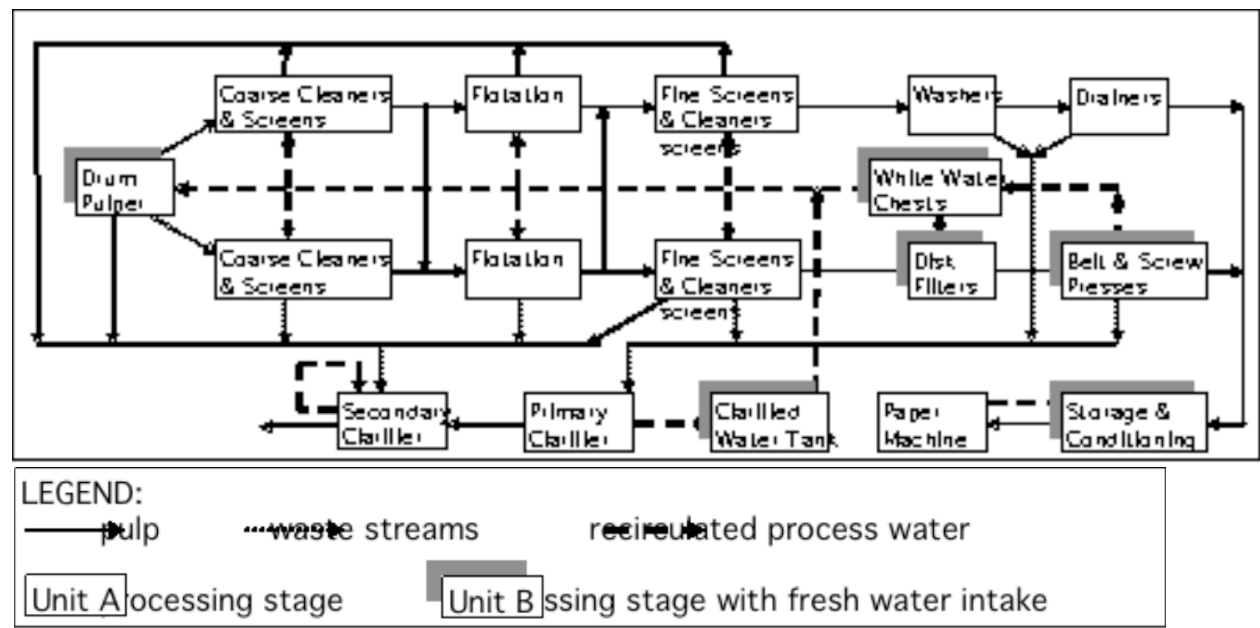

Figure 1. Process layout and water circulation

\section{METHODOLOGY}

A data reconciliation model has been built for the plant. This is an optimization model constituted by an objective function that corresponds to the minimization of the weighted errors on measurements and of a list of constraints representing the physics of the process operations. The constraints are mass and energy balances, separation rules, and thermodynamic behaviors. The model has been developed by using the equation solver type data reconciliation software VALI III (Belsim s.a, 2001).

A series of assumptions were made to build the model. Cellulose has been added in the compound data bank considering that only density properties were necessary, since the deinking process is almost isothermal. It was assumed that waste paper enters the pulper at $15^{\circ} \mathrm{C}$, that the temperature of fresh water and white water entering the system is set at $50^{\circ} \mathrm{C}$, that there is no heat loss from the process piping and equipment, and that output streams from units with multiple outlets are at equal temperature. Part of the pressure 
flow network was detailed with measurements from controller room printouts. Pressure drop was otherwise neglected.

The application of structural analysis of the incidence matrix allows analyzing the degree of redundancy of the control room measurements set, in order to identify missing and non validable measurements as well as the ones that can be corrected by measurement redundancy (Kalitventzeff and Joris, 1987). In the deinking plant additional sensors are required to obtain a satisfactory level of redundancy. In the proposed approach, an initial point has been obtained by compensating the lack of data by using data from previous studies of the original plant (Walosik, 1999; Bonhiver et al., 1998; Savu et al., 2001), updated with specifications from process control diagrams and laboratory test benchmark specifications of the upgraded plant. The results were then used to identify optimal sampling points for missing sensors. The resolution of this problem is done by using a genetic algorithm programming method (Heyen et al, 2002). The constrained data reconciliation problem is first transformed in an unconstrained one by using the Lagrange formulation:

$\operatorname{Min} L=(Y \square y)^{T} P(Y \square y)+\square F$

$X, Y, \square$

with $F=A Y+B$ and $P_{i i}=\frac{1}{\square_{i}^{2}}$, with $\square_{i}^{2}$ the standard deviation of measurement $\mathrm{i}$

In the new problem, the actual measurements have their own accuracy, while the unmeasured variables are considered as measured variables with a standard deviation that represents the use or not of a new sensor for this measurement. This is obtained by assigning an integer variable $\mathrm{y}_{\mathrm{i}, \mathrm{j}}$ that represents the use (1) or not (0) of the sensor of type $\mathrm{j}$ for the measurement $\mathrm{i}$.

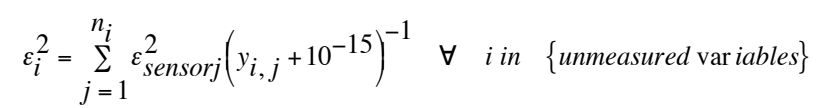

The objective function is computed by summing up the sensors costs and a sum of the measure $\left(\mathrm{P}_{\mathrm{i}}\right)$ of the projected standard deviation $\left(\square_{i}\right)$ of the key performance indicator $\mathrm{i}$ resulting from the sensitivity analysis matrix obtained by solving the linearized langrange formulation as defined by Heyen et al. (1996) :

$$
\text { IY }
$$

The method then operates in different steps starting with a verification of problem feasibility, assuming all available sensors have been implemented. This provides an upper limit for the cost of the system. The definition of the sensor system (values of the $\mathrm{y}_{\mathrm{i}, \mathrm{j}}$ ) are then defined using a genetic algorithm. 


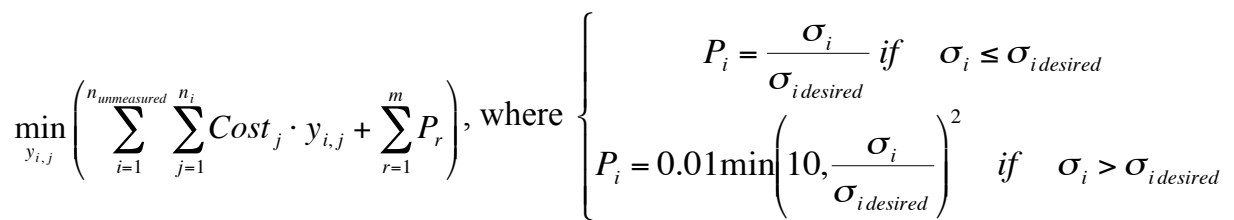

with $\quad \mathrm{n}_{\text {unmeaured }}$ : number of possible additional sensors.

$\mathrm{n}_{\mathrm{j}}$ the number of sensor types

$\mathrm{m}$ : number of key performance indicators.

\section{RESULTS AND DISCUSSION}

The data reconciliation and the sensor system configuration problem have been applied to sections of the plant for which controller room printouts were available: the pulper and the second pulp line. Table 1 presents an overview of the analysis of the incidence matrix of the system, when all measurements and modelization assumptions have been integrated to the model of this section of the plant.

\section{Table 1. Summary of the analysis of the incidence matrix}

\begin{tabular}{lclc}
\hline Number of equations & 405 & Number of additional measurements required & 79 \\
Number of unmeasured variables & 469 & Number of unmeasured variables which can be validated & 20 \\
Number of measured variables & 60 & Number of validable equations & 370 \\
Number of constants & 92 & Number of unvalidable measurements & 21 \\
Total number of redundancies & -64 & Equations with no influence on the validation problem & 20 \\
\hline
\end{tabular}

The next step consists in adding design specifications to compensate for the missing measurements. Five different types of measurements and specifications related to mass balances were used to build the model: consistency, flow rate, mass ratio of rejects or accepts from a separation unit (expressed as the ratio between inlet and outlet mass flows on an oven dried basis), the thickening ratio from a separation unit (expressed as the ratio of the outlet consistency on the inlet consistency), and finally flow rate ratios for split streams. In practice only volumetric flow and consistency can be measured by the plant's control system, whereas specifications expressed as ratios are related to equipment performance parameters indicated on process diagrams, and cannot be directly measured during plant operation. These types of specifications are useful because they confer the flexibility necessary to account for flow or consistency variations. Generally, consistency and pressure variations are monitored using smaller time constants in control loops. Hence, these parameters were preferred over flow when specifying dilution stream requirements from design specifications, the exception being when units such as pressure screens must operate at steady discharge.

Flow rate variations are tolerable due to the variability of the process. Indeed, it is preferable to consider the process diagram flow specifications as indicative values, rather than set specifications. When compared to design specifications, control room printouts indicate that input flow rates are not set. Also, production reports from the plant show that the total pulp output may vary considerably from day to day. In this respect, the validation model has to be flexible enough to be reconciled with different sets of data sampled at different points in time. For this reason, measured flow rate 
variables were often specified with larger inaccuracies than other variables. Table 2, compares global mass balances for the entire process, computed with raw data to the ones obtained by data reconciliation. Differences can be noted between flow variables left unspecified in the validated model (all streams except the paper intake).

Table 2. Process inlet and outlet flow rates and temperatures

\begin{tabular}{llcc}
\hline & STREAM DESCRIPTION & $\begin{array}{c}\text { SPECIFICATIONS } \\
\text { Flow }(\mathrm{kg} / \mathrm{s})\end{array}$ & $\begin{array}{c}\text { VALIDATION } \\
\text { Flow }(\mathrm{kg} / \mathrm{s})\end{array}$ \\
\hline INLETS & WATER & 77.20 & 78.14 \\
& PAPER & 6.74 & 6.74 \\
& WHITEWATER & 63.45 & 63.57 \\
\hline TOTAL IN & & $\mathbf{1 4 7 . 3 9}$ & $\mathbf{1 4 8 . 4 5}$ \\
\hline OUTLETS & SLUDGE & 2.20 & 2.28 \\
& SOLIDS & 0.47 & 0.45 \\
& EFFLUENT WATER & 55.86 & 56.90 \\
& PULP $(10 \% \mathrm{cs})$ & 18.88 & 18.42 \\
& PULP $(4.4 \% \mathrm{cs})$ & 70.18 & 70.40 \\
\hline TOTAL OUT & & $\mathbf{1 4 7 . 5 9}$ & $\mathbf{1 4 8 . 4 5}$ \\
\hline
\end{tabular}

For the sensor system design, two different cases have been considered. In the first case, ratio specifications are considered as constants, this implies that the units they refer to operate without any variability. This yields the minimum cost configuration capable of monitoring the overall process variability (e.g. the generally non-steady state behavior of the process due to breaks, start ups, slow downs, etc.). In the second case, ratio specifications are considered as variables so that the system may give an assessment of the accuracy of the performance of each individual separation unit. Measurements and design specifications of consistency and flow rate are considered as variables in both cases. The original configuration includes 43 sensors. The constant ratio specification configuration would require 47 additional sensors, while the variable ratio specification configuration would require 97 . Numbers and types of the different sensors for the optimal sensor system are presented in table 3. Annualized costs and accuracies of sensors are obtained from component price guides, and other industrial sources (Gerkens, 2002). These include pressure, temperature, flow, and consistency measuring devices.

Table 3. Summary of the sensor system optimization and sensor costs

\begin{tabular}{|c|c|c|c|c|c|}
\hline & & \multicolumn{2}{|c|}{ Constant Ratio Specifications } & \multicolumn{2}{|c|}{ Variable Ratio Specifications } \\
\hline \multicolumn{2}{|c|}{ Number of possible sensors } & \multicolumn{2}{|c|}{361} & \multicolumn{2}{|c|}{385} \\
\hline Maximum cost (upper & iit) $(€)$ & \multicolumn{2}{|l|}{209,100} & \multicolumn{2}{|c|}{223,600} \\
\hline \multicolumn{6}{|c|}{ Best solution after 1201 generations } \\
\hline \multicolumn{2}{|c|}{ Additional sensors required } & \multicolumn{2}{|l|}{47} & \multicolumn{2}{|c|}{97} \\
\hline \multicolumn{2}{|c|}{ Annualized cost of additional sensors $(€)$} & \multicolumn{2}{|l|}{22,400} & \multicolumn{2}{|c|}{53,200} \\
\hline \multirow{2}{*}{$\begin{array}{c}\text { SENSOR } \\
\text { (\# of different types) }\end{array}$} & ANNUALIZED & ACCURACY & \multicolumn{3}{|c|}{ NUMBER OF SENSORS } \\
\hline & $(€)$ & & Present & Constant R.S* & Variable R.S* \\
\hline Temperature (1) & 520 & $1.5^{\circ} \mathrm{C}$ & 0 & 11 & 19 \\
\hline Pressure (1) & 510 & $1.5 \%$ & 30 & 50 & 56 \\
\hline Volumetric flow (2) & $570 \& 1,000$ & $1.5 \%$ & 8 & 16 & 30 \\
\hline Consistency (6) & 500 to 1,000 & $1 \%$ & 5 & 13 & 36 \\
\hline Total & - & - & 43 & 90 & 141 \\
\hline
\end{tabular}

\footnotetext{
* RS: Ratio specifications
} 


\section{CONCLUSIONS}

Data reconciliation has been applied to build a validated model of a waste paper deinking plant. Controller measurements were combined with equipment and process design specifications, to compensate for missing data. Despite the fact that the inputs to the process may vary greatly, the model is still generally consistent because ratio design specifications allow accounting for measurement variability.

A method based on the sensitivity analysis and genetic algorithm programming has been applied to design the optimal sensor system capable of computing the plants key performance indicators with a satisfactory accuracy at minimum cost. This would allow building a validation model by using only sensor measurements but requires doubling or tripling the number of sampling points.

\section{ACKNOWLEDGEMENTS}

The EU-Canada Cooperation Agreement on Higher Education and Training Academic Mobility Program from HRD Canada and MRN Québec, have contributed to funding this project. The authors would also like to thank the plant's staff for providing time and information towards the realization of the study.

\section{REFERENCES}

Belsim, VALI 3 User's Guide, Belsim s.a, St-Georges-sur-Meuse, Belgium, 2001.

Bonhivers, J.C., S. Belon-Gagnon, J.Paris, "Simulation dynamique de l'atelier de désencrage de l'usine de Kruger à Bromptonville, Québec”, Reference manual, Ecole Polytechnique, Montreal, Canada, 1998.

Gerkens, C., "Conception Rationnelle de systèmes de mesure dans les procédés chimiques” Final project, Ulg, Liège, Belgium, 2002.

Heyen G., E. Maréchal and B. Kalitventzeff, "Sensitivity Calculations and Variance Analysis in Plant Measurement Reconciliation”, Computers and Chemical Engineering, vol. 20S, 539-544, 1996.

Heyen, G., “Application of Data Reconciliation to Process Monitoring” Symposium ISCAPE 2000, Carthagena de Indias, Colombia, 2000.

Heyen, G., M.N. Dumont and B. Kalitventzeff, “Computer-Aided Design of Redundant Sensor Networks”, ESCAPE 12, The Hague, Netherlands, 2002.

Jacob, J. and J. Paris, "Data Sampling and Reconciliation, Application to Pulp and Paper Mills” Appita Journal, Canada, in print.

Kalitventzeff, B. and P. Joris., "Process Measurements Analysis and Validation", CEF87, The Use of Computers in Chemical Engineering, Taormina, Italy, 1987.

Savu, E., S. Sarailh, F. Maréchal and J. Paris, "Impact de la fermeture des circuits dans un procédé de désencrage", P\&P Can (to be published), et in preprints, $6^{\text {th }}$ Research Forum on Recycling, 155-158, Magog, Canada, 2001.

Walosik, S., "Gestion de l'eau dans le procédé de désencrage/ problématique et étude de cas”, Masters thesis, Ecole Polytechnique, Montreal, Canada, 1999. 